\title{
Electrical Activities and Pressure Pain Threshold in Oral Contraceptives Users and Nonusers
}

\author{
Karina Helga Leal Turcio ${ }^{\text {* }}$, Alício Rosalino Garcia1, Paulo Renato Junqueira Zuim1, \\ Maria Lucia Marçal Mazza Sundefeld², Marcelo Coelho Goiato'1, Daniela Micheline dos Santos ${ }^{1}$ \\ ${ }^{1}$ Department of Dental Materials and Prosthodontics, Faculty of Dentistry of Araçatuba, Universidade Estadual \\ Paulista-UNESP, Araçatuba, São Paulo, Brazil \\ ${ }^{2}$ Department of Biostatistics, Faculty of Dentistry of Araçatuba, Universidade Estadual Paulista-UNESP, \\ Araçatuba, São Paulo, Brazil \\ Email: ${ }^{*}$ Karina@foa.unesp.br
}

Received 5 February 2014; revised 5 March 2014; accepted 11 April 2014

Copyright (C) 2014 by authors and Scientific Research Publishing Inc.

This work is licensed under the Creative Commons Attribution International License (CC BY). http://creativecommons.org/licenses/by/4.0/

\section{Open Access}

\section{Abstract}

The aim is to evaluate the influence of oral contraceptive intake and menstrual cycle on the electrical activity and pressure pain threshold from anterior temporal and masseter muscles. Twenty-eight women on reproductive age were selected, 13 OC users and 15 nonusers. They were weekly submitted to electromyography and algometry of the anterior temporal and masseter muscles during three consecutive menstrual cycles. Electrical activities at rest position and PPTs of temporal and masseter muscles were not affected by menstrual cycle or by OCs uses. Comparison between groups demonstrated that working side electrical activity was increased in OC users in both muscles, except during lutheal phase for the anterior temporal. However, comparison within weeks did not demonstrate statistical difference. It was suggested that, in healthy women, oral contraceptive use may influence electrical activity, but different phases of the cycle may not.

\section{Keywords}

Menstrual Cycle, Pressure Pain Threshold, Electromiography, Oral Contraceptives, Sexual Hormones

\section{Introduction}

Temporomandibular disorders (TMD) are more frequently observed in women than in men, and $80 \%$ of treated

"Corresponding author. 
cases are females [1]. This high predilection has been associated to reproductive hormones and constitutional factors [2]-[4]. Age and gender can influence the muscular function and thickness and men have a greater muscular potential as compared to women [5] [6]. The hypothesis of a gender-dependent risk profile for signs of TMD is partly supported. The gender-dependent risk profile for signs of TMD is cited by some authors [7]. Some studies demonstrated pressure pain thresholds (PPTs) variations across menstrual cycles, but, results are still conflicting [2] [8] [9].

Also, the prescription of exogenous estrogen in the form of estrogen replacement in menopause or oral contraceptives during reproductive years may increase the risk of TMD [10] [11]. Some authors verified a slightly increased risk of TMD for oral contraceptives (OCs) users; however they could not attribute their results to a specific hormone, because the majority of pills were combination of estrogen and progestin [11]. Others did not find increased risk of developing TMD in OCs users [12]. In a recent study, it was verified that different phases of the menstrual cycle have no influence on PPT values, regardless of the presence of a previous condition, as masticatory myofascial pain, while the intake of OC is associated with decreased levels of reported pain [13]. In other study, phase-related differences in experimental pain response were not strong [14].

Menstrual cycle is a process associated with significant changes in hormonal status and behavior [15]. It is, therefore, not surprising that hormone variations occurred during the cycle has been found to be associated to a psychophysical variation and sensitivity to noxious stimuli [16].

It is possible that an association between reproductive hormones and pain exists, as well, pressure-pain threshold alteration, stress and anxiety in women. However, the already published studies still present conflicting results, and it is important to have more studies with non-symptomatic individuals because it decreases some patient variables. Therefore, the aim of the present study was to evaluate the influence of the intake of OC and menstrual cycle on the electrical activity and pressure pain threshold from anterior temporal and masseter muscles.

\section{Methods}

\subsection{Subjects}

Thirty females in reproductive age were initially recruited for this study. All volunteers were examined according to the Research Diagnostic Criteria for Temporomandibular Disorders (RCD/TMD) [17] presented no signs and symptoms of TMD. Twenty eight females between 18 and 32 years old were included in the study, as two of them failed to return at appointments. Fifteen of them were not OC users and were not users of any form of hormones (Group 1 - G1). The other thirteen were OCs users (Group 2 - G2). The Group 1 presented regular menstrual cycles (28 \pm 3 days) and they had not taken OCs for at least three months. Women using OCs had to be using low dose pills (estrogen and progesterone combination) for at least three months [2]. The OC group was taking exogenous sex hormones only for contraceptive purposes, confirmed by the volunteer's physician. The OC were required to be used in a cycle of 21 days for active medication followed by 7 days without active medication. They were students at Araçatuba School of Dentistry, University of the State of São Paulo, Brazil.

They were also free from metabolites and neural diseases, gynecologic disorders, migraine, chronic abdominal pain, psychiatric disorder and not being treated for any pathology or using any chronic medications. Patients missing teeth (excluding third molar) were also excluded.

The selected subjects were informed about the research and signed an informed consent form in accordance with the recommendations of the Human Research Ethics Committee (FOA-UNESP-2004-01162).

\subsection{Experimental Protocol}

Each subject received oral information about procedures of the study, but they were not informed about the hypothesis. They were examined weekly during three consecutive menstrual cycles and the exams initiated at first day of menses of the first month. The menstrual cycle was divided into four distinct phases starting at: (1) 1st day of menstruation to 2 days after; (2), $7^{\text {th }}$ day \pm 2 days: (3,) $14^{\text {th }}$ day \pm 2 days; and (4) $21^{\text {st }}$ day \pm 2 days. They were instructed not to take any analgesic medication before exams [18].

Women who were not on OC group predicted their ovulation. They were instructed in how to use the ClearPlan (ClearPlan Easy, Unipath Research, Princeton, NJ) ovulation prediction kit and received enough kits for the first cycle.

They were submitted to electromyographic (EMG) measurements and algometry. Al results of the exams 
were recorded to posterior comparison and analysis.

Prior to EMG measurements subjects were questioned about their preferred chewing side (PCS) and it was registered. All subjects were evaluated by the same professional previously trained for EMG exams and algometry.

\subsection{EMG Measurements}

All subjects were submitted to EMG measurements weekly according to menstrual cycle phases cited above. During the EMG recordings, the subjects were kept in a comfortable sitting position with no headrest, with the Frankfort horizontal plane parallel to the floor [19].

Prior to installation of electrodes, the skin overlying right and left anterior temporal and masseter muscles, as well as the right side of the neck was cleaned with water, toilet soap and alcohol to reduce impedance and enhance signal conductivity. The patients were asked to clench so that the investigated muscle could be palpated, allowing the localization for placement of surface electrodes [18]. The most prominent part of the major muscle mass of the anterior temporal was determinated by digital palpation. The masseter muscle was also palpated and localized.

The bipolar surface electrodes (BioResearch, USA) applied were disposable duotrodes, which were $10 \mathrm{~mm}$ in diameter. A 21-mm inter-electrode distance was utilized and the electrodes were connected to an amplifier by cables, which was in turn connected to a computer with Bioresearch 'Bio EMG' (USA) software installed, allowing the electrical signal to be captured and the electrical activity of the muscles to be analyzed. The following parameters were utilized: sampling rate $1000(\mathrm{~Hz})$, sample length 15 (s) and amplification $1 \mathrm{X}$. Electrodes were seated bilaterally over dry skin parallel to the muscle fibers at the prominent part of the major muscle mass of the anterior temporal and at the middle of masseter muscle. The EMG activity was recorded at 1) the mandibular rest position; 2) During unilateral chewing of three raisins on the patient's PCS and at the opposite side. During mandibular rest EMG activities were recorded at the 2nd, 4th, 6th and 8th seconds, and during chewing, EMG activity was recorded at four alternated clenches.

\subsection{Algometry (Pressure Pain Threshold)}

Before the procedure started, volunteers were carefully instructed about the significance of PPT and a few tests were performed on their hands [13].

Volunteers were sat in a dental chair in an upright position described above. Both sides of the face were evaluated and they were identified as PCS and non-PCS. The PPT was determined as the point where the pressure stimulus applied to the skin change from sensation of pressure to pain [13]. The PPTs were evaluated by means of an algometer "Wagner model FPK 5". The tip of the probe has a circular rubber tip with an area of $1 \mathrm{~cm}^{2}$, and a $5 \mathrm{~cm}$ hook. The local for placement of the rubber tip was the most prominent area of the major muscle mass of the anterior temporal and masseter one during clenching. Prior to algometry, subject was asked to relax and maintain the jaw in rest position. Then, the investigator supported the patient head with one hand on the opposite side of the pressure point during algometry. The PPT was determined as the point at which the pressure stimulus applied to the skin change from sensation of pressure to pain [13]. The volunteers indicated the PPT by elevating hand when they have had identified painful sensation. Three measurements were made at each visit, with a 5-minute rest interval between trials [20] and the first pressured point was randomized selected. The PPT was calculated by averaging the 3 measurements.

The EMG activity and PPTs means of every week of three menstrual cycles were considered for statistical analysis. The different phases or weeks of each group could be compared and different groups could be compared.

PPTs and EMG measurements at rest position were evaluated on PCS and non-PCS. At chewing tests only working side was analyzed while subjects chewed on both sides.

\subsection{Statistical Analyses}

The Variance Analysis $(\mathrm{p}<0.05)$ for repeated measures designs was performed to compare groups and it was followed by Tukey's test to elucidate the group differences at each week of menstrual cycle $(\mathrm{p}<0.05)$.

\section{Results}

Statistical differences between groups were not detected at rest position on both sides (Temporal muscle: PCS, ANOVA; $\mathrm{p}=0.12$ and non-PCS, ANOVA; $\mathrm{p}=0.13$; Masseter muscle: PCS, ANOVA; $\mathrm{p}=0.26$ and on non- 
PCS, ANOVA; p = 0.09) (Table 1 and Table 2).

ANOVA has shown statistically higher electrical activities from anterior temporal muscle on the working side in OC users (G2) on PCS ( $=0.0004)$ and non-PCS ( $=0.0005)$; during chewing (Table 3$)$. The within groups analysis has shown difference on correspondent weeks on both sides (Tukey's test; $\mathrm{p}<0.05$ ) except in luteal phase of non-PCS (Tukey's test; $p>0.05$ ). Masseter muscles activity from the working side chewing from G2 was also significantly elevated when compared to that from G1 on PCS (ANOVA; $p=0.0019$ ) and non-PCS ( $p$ $=0.018$ ) (Table 4). The within weeks analysis has shown no difference on both sides (Tukey's test; $p>0.05$ ).

Anterior temporal and masseter muscle PPTs on the working side of chewing were not statistically different (ANOVA; $\mathrm{p}=0.46 ; \mathrm{p}=0.55$, respectively; Tukey's test; $\mathrm{p}>0.005$ ) although OC users have had lower PPT than non-OC users (Table 5 and Table 6).

\section{Discussion}

A number of authors have studied the possible relationship between sexual differences and orofacial pain [2]-[5] [8]-[10] [13] [18]. Methodological differences and problems associated with most experimental pain studies, however, do not provide any definitive conclusion [13].

Table 1. Anterior temporal electrical activity at rest position $(\mu v)$.

\begin{tabular}{ccccc}
\hline & \multicolumn{2}{c}{ G1 } & PSC & Non-PSC \\
\hline Phase Side & PSC & Non-PSC & $1.53 \pm 0.13 \mathrm{~A} \mathrm{a}$ & $1.46 \pm 0.10 \mathrm{~A} \mathrm{a}$ \\
\hline 1 & $1.61 \pm 0.10 \mathrm{~A} \mathrm{a}$ & $1.78 \pm 0.13 \mathrm{~A} \mathrm{a}$ & $1.53 \pm 0.08 \mathrm{~A} \mathrm{a}$ & $1.69 \pm 0.09 \mathrm{~A} \mathrm{a}$ \\
2 & $1.79 \pm 0.13 \mathrm{~A} \mathrm{a}$ & $1.78 \pm 0.09 \mathrm{~A} \mathrm{a}$ & $1.54 \pm 0.07 \mathrm{~A} \mathrm{a}$ & $1.71 \pm 0.14 \mathrm{~A} \mathrm{a}$ \\
3 & $1.54 \pm 0.10 \mathrm{~A} \mathrm{a}$ & $1.73 \pm 0.08 \mathrm{~A} \mathrm{a}$ & $1.55 \pm 0.10 \mathrm{~A} \mathrm{a}$ & $1.62 \pm 0.20 \mathrm{~A} \mathrm{a}$ \\
\hline
\end{tabular}

Same uppercase letter indicates no differences in column $(\mathrm{p}>0.05)$. Same lowercase letter indicates no differences in row $(\mathrm{p}>0.05)$.

Table 2. Masseter electrical activity at rest position $(\mu \mathrm{v})$.

\begin{tabular}{|c|c|c|c|c|}
\hline \multirow[b]{2}{*}{ Phase Side } & \multicolumn{2}{|c|}{ G1 } & \multicolumn{2}{|c|}{ G2 } \\
\hline & PSC & Non-PSC & PSC & Non-PSC \\
\hline 1 & $1.38 \pm 0.06 \mathrm{~A} \mathrm{a}$ & $1.15 \pm 0.10 \mathrm{~A} \mathrm{a}$ & $1.52 \pm 0.05 \mathrm{~A} \mathrm{a}$ & $1.54 \pm 0.12 \mathrm{~A} \mathrm{a}$ \\
\hline 2 & $1.44 \pm 0.06 \mathrm{~A} \mathrm{a}$ & $1.51 \pm 0.06 \mathrm{~A} \mathrm{a}$ & $1.49 \pm 0.07 \mathrm{~A} \mathrm{a}$ & $1.35 \pm 0.07 \mathrm{~A} \mathrm{a}$ \\
\hline 3 & $1.47 \pm 0.07 \mathrm{~A} \mathrm{a}$ & $1.49 \pm 0.08 \mathrm{~A} \mathrm{a}$ & $1.45 \pm 0.08 \mathrm{~A} \mathrm{a}$ & $1.30 \pm 0.06 \mathrm{~A} \mathrm{a}$ \\
\hline 4 & $1.37 \pm 0.04 \mathrm{~A} \mathrm{a}$ & $1.44 \pm 0.05 \mathrm{~A} \mathrm{a}$ & $1.40 \pm 0.08 \mathrm{~A} \mathrm{a}$ & $1.36 \pm 0.05 \mathrm{~A} \mathrm{a}$ \\
\hline
\end{tabular}

Same uppercase letter indicates no differences in column $(\mathrm{p}>0.05)$. Same lowercase letter indicates no differences in row $(p>0.05)$.

Table 3. Anterior temporal electrical activity on the working side of chewing $(\mu \mathrm{v})$.

\begin{tabular}{ccccc}
\hline & \multicolumn{2}{c}{ G1 } & \multicolumn{2}{c}{ G2 } \\
\hline Phase Side & PSC & Non-PSC & PSC & Non-PSC \\
\hline 1 & $40.08 \pm 3.49 \mathrm{~A} \mathrm{a}$ & $36.64 \pm 4.00 \mathrm{~A} \mathrm{a}$ & $52.68 \pm 4.04 \mathrm{~B}$ a & $54.32 \pm 5.57 \mathrm{~B} \mathrm{a}$ \\
2 & $39.3 \pm 3.10 \mathrm{~A} \mathrm{a}$ & $36.14 \pm 4.49 \mathrm{~A} \mathrm{a}$ & $54.99 \pm 7.42 \mathrm{~B} \mathrm{a}$ & $54.4 \pm 6.78 \mathrm{~B} \mathrm{a}$ \\
3 & $42.42 \pm 5.25 \mathrm{~A} \mathrm{a}$ & $37.97 \pm 4.94 \mathrm{~A} \mathrm{a}$ & $51.98 \pm 5.06 \mathrm{~B} \mathrm{a}$ & $53.22 \pm 6.38 \mathrm{~B} \mathrm{a}$ \\
4 & $39.18 \pm 3.30 \mathrm{~A} \mathrm{a}$ & $37.25 \pm 4.69 \mathrm{~A} \mathrm{a}$ & $51.72 \pm 6.42 \mathrm{~B} \mathrm{a}$ & $50.67 \pm 5.75 \mathrm{~B} \mathrm{a}$ \\
\hline
\end{tabular}

Same uppercase letter indicates no differences in column ( $p>0.05$ ). Same lowercase letter indicates no differences in row $(\mathrm{p}>0.05)$. 
Table 4. Masseter electrical activity on the working side of chewing ( $\mu \mathrm{v})$.

\begin{tabular}{ccccc}
\hline & \multicolumn{2}{c}{ G1 } & \multicolumn{2}{c}{ G2 } \\
\hline Phase Side & PSC & Non-PSC & PSC & Non-PSC \\
\hline 1 & $61.15 \pm 6.74$ & $66.36 \pm 6.44$ & $76.12 \pm 7.51$ & $82.85 \pm 9.91$ \\
2 & $63.52 \pm 6.10$ & $69.25 \pm 7.55$ & $82.45 \pm 11.33$ & $81.48 \pm 9.10$ \\
3 & $62.15 \pm 6.76$ & $69.63 \pm 5.61$ & $79.64 \pm 10.69$ & $80.64 \pm 8.51$ \\
4 & $62.18 \pm 5.76$ & $71.30 \pm 6.57$ & $76.97 \pm 9.11$ & $84.17 \pm 9.43$ \\
\hline
\end{tabular}

Table 5. Anterior temporal pressure pain threshold of muscle at rest position $\left(\mathrm{kgf} / \mathrm{cm}^{2}\right)$.

\begin{tabular}{ccccc}
\hline & \multicolumn{2}{c}{ G1 } & \multicolumn{2}{c}{ G2 } \\
\hline Phase Side & PSC & Non-PSC & PSC & Non-PSC \\
\hline 1 & $1.56 \pm 0.13 \mathrm{~A} \mathrm{a}$ & $1.64 \pm 0.13 \mathrm{~A} \mathrm{a}$ & $1.41 \pm 0.11 \mathrm{~A} \mathrm{a}$ & $1.51 \pm 0.09 \mathrm{~A} \mathrm{a}$ \\
2 & $1.65 \pm 0.11 \mathrm{~A} \mathrm{a}$ & $1.76 \pm 0.15 \mathrm{~A} \mathrm{a}$ & $1.46 \pm 0.12 \mathrm{~A} \mathrm{a}$ & $1.57 \pm 0.10 \mathrm{~A} \mathrm{a}$ \\
3 & $1.69 \pm 0.12 \mathrm{~A} \mathrm{a}$ & $1.87 \pm 0.16 \mathrm{~A} \mathrm{a}$ & $1.54 \pm 0.12 \mathrm{~A} \mathrm{a}$ & $1.56 \pm 0.10 \mathrm{~A} \mathrm{a}$ \\
4 & $1.63 \pm 0.13 \mathrm{~A} \mathrm{a}$ & $1.77 \pm 0.16 \mathrm{~A} \mathrm{a}$ & $1.53 \pm 0.12 \mathrm{~A} \mathrm{a}$ & $1.52 \pm 0.10 \mathrm{~A} \mathrm{a}$ \\
\hline
\end{tabular}

Same uppercase letter indicates no differences in column $(\mathrm{p}>0.05)$. Same lowercase letter indicates no differences in row $(\mathrm{p}>0.05)$.

Table 6. Masseter pressure pain threshold of muscle at rest position $\left(\mathrm{kgf} / \mathrm{cm}^{2}\right)$.

\begin{tabular}{ccccc}
\hline & \multicolumn{2}{c}{ G1 } & G2 \\
\hline Phase Side & PSC & Non-PSC & PSC & Non-PSC \\
\hline 1 & $1.35 \pm 0.10 \mathrm{~A} \mathrm{a}$ & $1.45 \pm 0.11 \mathrm{~A} \mathrm{a}$ & $1.24 \pm 0.08 \mathrm{~A} \mathrm{a}$ & $1.31 \pm 0.09 \mathrm{~A} \mathrm{a}$ \\
2 & $1.40 \pm 0.08 \mathrm{~A} \mathrm{a}$ & $1.52 \pm 0.10 \mathrm{~A} \mathrm{a}$ & $1.30 \pm 0.08 \mathrm{~A} \mathrm{a}$ & $1.40 \pm 0.10 \mathrm{~A} \mathrm{a}$ \\
3 & $1.43 \pm 0.10 \mathrm{~A} \mathrm{a}$ & $1.60 \pm 0.12 \mathrm{~A} \mathrm{a}$ & $1.30 \pm 0.07 \mathrm{~A} \mathrm{a}$ & $1.37 \pm 0.10 \mathrm{~A} \mathrm{a}$ \\
4 & $1.42 \pm 0.12 \mathrm{~A} \mathrm{a}$ & $1.51 \pm 0.13 \mathrm{~A} \mathrm{a}$ & $1.34 \pm 0.10 \mathrm{~A} \mathrm{a}$ & $1.36 \pm 0.09 \mathrm{~A} \mathrm{a}$ \\
\hline
\end{tabular}

Same uppercase letter indicates no differences in column $(\mathrm{p}>0.05)$. Same lowercase letter indicates no differences in row $(\mathrm{p}>0.05)$.

The hypothesis that PPTs of masticatory muscles are influenced by the phases of the ovarian cycle is accepted in some studies [2] [8] [9] [18] [19] and rejected by others, [13] but the results are still contradictory.

Vignolo et al. (2008), [13] showed masseter PPTs varying from 1.24 to $1.36 \mathrm{kgf} / \mathrm{cm}^{2}$ in non-OC users and from 1.29 a $1.66 \mathrm{kgf} / \mathrm{cm}^{2}$ in OC users, and temporal PPTs varying from 1.75 to $1.84 \mathrm{kgf} / \mathrm{cm}^{2}$ and from $1.81 \mathrm{a}$ $2.11 \mathrm{kgf} / \mathrm{cm}^{2}$ respectively in G1 and G2. Our results demonstrated masseter PPTs varying from 1.35 to 1.60 $\mathrm{kgf} / \mathrm{cm}^{2}$ in $\mathrm{G} 1$ and from 1.24 to $1.40 \mathrm{kgf} / \mathrm{cm}^{2}$ in G2. And temporal PPTs varying from 1.56 to $1.87 \mathrm{kgf} / \mathrm{cm}^{2}$ in $\mathrm{G} 1$ and from 1.41 to $1.57 \mathrm{kgf} / \mathrm{cm}^{2}$ in G2. The values were numerically different but PPT was not influenced by menstrual cycle phases in both studies. Our results did not demonstrate difference on PPTs within weeks. The results also showed a tendency of PPTs to be increased in OCs users.

The determination of menstrual cycle based on temporal cycle day criteria alone may not be considered accurate and it may cause variability of results [18]. At present study, two out of the four phases could specifically be determinated: the menstruation one, confirmed by subject; and the ovulation one, predicted by ovulation kit. Therefore, we could recognize phases with a high grade of security.

Pain has been associated to hyperactivity [21] [22] but there are no studies associating muscle activities with menstrual cycle and oral contraceptive uses. Since oral contraceptives are being suggested to increase pain and risk of TMD, [11] [12] the present study intended to evaluate the influence of oral contraceptive intake and menstrual cycle on the electrical activity and pressure pain threshold from anterior temporal and masseter mus- 
cles. A number of studies used rest position to analyses alterations in muscle electrical activity [21]-[23] [25] [26]. As our study was performed with asymptomatic women, we did not find any variation in electrical activity at rest position of oral muscles PPTs during different phases of the menstrual cycle. No difference was found between OC users and non-OC users as well. These last results are in accordance with a recent study [13]. We can, then, suggest that hormone fluctuations across menstrual cycle may not affect muscle activity during rest and that OCs may not affect this activity by itself.

Anterior temporal electrical activity during chewing at the PCS was significantly increased in OC users group, when compared to non-PCS (exception to luteal phase in the last side). A literature review [26] cited that plasma and brain concentration of some neuroactive steroids are reduced by OC treatment, and since these steroids are supposed to play a potential role on mood regulation, OCs are also supposed to be associated to some mood disorders. In this way, chewing muscles may be affected by emotional alterations; maybe OCs treatment could alter muscles reactions to masticatory force.

Electrical activity from masseter muscle was not statistical different among phases within each group. It was though, higher in all phases of menstrual cycle for OC users.

At present study OC users does not demonstrate decreased PPT regardless of increased electrical activity during chewing. The literature concerning the influence of exogenous hormones on TMD is contradictory. Oral contraceptives use was also associated with referral for TMD care, with an increased risk of TMD [11] [12] [27]. We observed a tendency of PPT be decreased in this group (G2). We can suggest that PPT is influenced by others factors that need to be investigated. A study [18] suggested that the PPTs of several masticatory muscles are influenced by the ovarian cycle, but to a minor extent, and the influence is of limited clinical relevance. It is also important to remember that a tissue response to hormone fluctuation depends on the presence and amount of specific hormone receptors [26].

Fluctuations in pain threshold across the menstrual cycle, seems to be more relevant in subjects with temporomandibular disorders, [13] especially articular ones [28].

\section{Conclusion}

Considering this, we conclude that electrical activities of anterior temporal and masseter during chewing were influenced by OCs and that the rest electrical activities didn't fluctuate across menstrual cycle. And, in asymptomatic subjects, the PPT was not affected by OCs use and menstrual cycle.

\section{References}

[1] Dworkin, S.F., Huggins, K.H., Leresche, L., Von Korff, M., Howard, J., Truelove E. and Sommers E. (1990) Epidemiology of Signs and Symptoms in Temporomandibular Disorders: Clinical Signs in Cases and Controls. JADA, 120, 273-281.

[2] LeResche, L., Mancl, L., Sherman, J., Gandara, B. and Dworkin, S.F. (2003) Changes in Temporomandibular Pain and Other Symptoms across the Menstrual Cycle. Pain, 106, 253-261. http://dx.doi.org/10.1016/j.pain.2003.06.001

[3] Riley, J.L., Robinson, M.E., Wise, E.A., Myers, C.D. and Fillingim, R.B. (1998) Sex Differences in the Perception of Noxious Experimental Stimuli: A Meta-Analysis. Pain, 74, 181-187.

http://dx.doi.org/10.1016/S0304-3959(97)00199-1

[4] Unruh, A.M. (1996) Gender Variations in Clinical Pain Experience. Pain, 65, 123-167. http://dx.doi.org/10.1016/0304-3959(95)00214-6

[5] Palinkas, M., Nassar, M.S.P., Cec1lio, F.A., Siessere, S., Semprini, M., Machado-de-Sousa, J.P., Hallak, J.E.C. and Regalo, S.C.H. (2010) Age and Gender Influence on Maximal Bite Force and Masticatory Muscles Thickness. Archives of Oral Biology, 55, 797-802. http://dx.doi.org/10.1016/j.archoralbio.2010.06.016

[6] Newton, J.P., Yemm, R., Abel, R.W. and Menhinick, S. (1993) Changes in Human Jaw Muscles with Age and Dental State. Gerodontology, 10, 16-22. http://dx.doi.org/10.1111/j.1741-2358.1993.tb00074.X

[7] Mundt, T., Mack, F., Schwahn, C., Bernhardt, O., Kocher, T. and Biffar, R. (2008) Association between Sociodemographic, Behavioral, and Medical Conditions and Signs of Temporomandibular Disorders across Gender: Results of the Study of Health in Pomerania (SHIP-0). International Journal of Prosthodontics, 21, 141-148.

[8] Isselée, H., De Laat, A., Bogaerts, K. and Lysens, R. (2001) Long-Term Fluctuations of Pressure Pain Thresholds in Healthy Men, Normally Menstruating Women and Oral Contraceptive Users. European Journal of Pain, 5, 27-37. http://dx.doi.org/10.1053/eujp.2000.0213 
[9] Hellström, B. and Anderberg, U.A. (2003) Pain Perception across the Menstrual Cycle Phases in Women with Chronic Pain. Percept Mot Skills, 96, 201-211. http://dx.doi.org/10.2466/pms.2003.96.1.201

[10] Dao, T.T.T., Knight, K. and Ton-That, V. (1998) Modulation of Myofascial Pain by the Reproductive Hormones: A Preliminary Report. Journal of Prosthetic Dentistry, 79, 663-670. http://dx.doi.org/10.1016/S0022-3913(98)70073-3

[11] LeResche, L., Saunders, K., Von Korff, M., Barlow, W. and Dworkin, S.F. (1997) Use of Exogenous Hormones and Risk of Temporomandibular Disorder Pain. Pain, 69, 153-160. http://dx.doi.org/10.1016/S0304-3959(96)03230-7

[12] Hatch, J.P, Rugh, J.D., Sakai, S. and Saunders, M.J. (2001) Is Use of Exogenous Associated with Temporomandibular Signs and Symptoms? JADA, 132, 319-325. http://dx.doi.org/10.14219/jada.archive.2001.0174

[13] Vignolo, V., Vedolin, G.M., de Araujo, Cdos R. and Conti, P.C.R. (2008) Influence of the Menstrual Cycle on the Pressure Pain Threshold of Masticatory Muscles in Patients with Masticatory Myofascial Pain. Oral Surgery, Oral Medicine, Oral Pathology, Oral Radiology, and Endodontics, 105, 308-315. http://dx.doi.org/10.1016/j.tripleo.2007.08.044

[14] Sherman, J.J., LeResche, L., Mancl, L.A., Huggins, K., Sage, J.C. and Dworkin, S.F. (2005) Cyclic Effects on Experimental Pain Response in Women with Temporomandibular Disorders. Journal of Oral \& Facial Pain and Headache, 19, 133-143.

[15] Milewicz, A. and Jedrzejuk, D. (2006) Premenstrual Syndrome: From Etiology to Treatment. Maturitas. International Symposium on Phytomedicines in Gynecology, 55, S47-S54.

[16] Fillingim, R.B. and Maixner, W. (1995) Gender Differences in the Responses to Noxious Stimuli. Pain Forum, 4, 209221.

[17] Dworkin, S.F. and LeResche, L. (1992) Research Diagnostic Criteria for Temporomandibular Disorders: Review, Criteria, Examinations and Specifications, Critique. Journal of Craniomandibular Disorder, 6, 301-355.

[18] Cimino, R., Farella, M., Michelotti, A., Pugliesse, R. and Martina, R. (2000) Does the Ovarian Cycle Influence the Pressure-Pain Threshold of the Masticatory Muscles in Symptom-Free Women? Journal of Orofacial Pain, 14, 105111.

[19] Drobek, W., Schoenaers, J. and De Laat, A. (2002) Hormone Dependent Fluctuation of Pressure Pain Threshold and Tactile Threshold of the Temporalis and Masseter Muscle. Journal of Oral Rehability, 29, 1042-1051. http://dx.doi.org/10.1046/j.1365-2842.2002.00988.x

[20] Landulpho, A.B., Silva, W.A., Silva, F.A. and Vitti, M. (2004) Electromyographic Evaluation of Masseter and Anterior Temporalis Muscles in Patients with Temporomandibular Disorders Following Interocclusal Appliance Treatment. Journal of Oral Rehability, 31, 95-98. http://dx.doi.org/10.1046/j.0305-182X.2003.01204.x

[21] Gervais, O.R., Fitzsimmons, G.W. and Thomas, R.N. (1989) Masseter and Temporalis Electromyographic Activity in Asymptomatic, Subclinical, and Temporomandibular Joint Dysfunction Patients. Cranio, 7, 52-57.

[22] Schoenen, J., Bottin, D., Hardy, F. and Gerard, P. (1991) Cephalic and Extracephalic Pressure Pain Thresholds in Chronic Tension-Type Headache. Pain, 47, 145-149. http://dx.doi.org/10.1016/0304-3959(91)90198-7

[23] Bodere, C., Téa, S.H., Giroux-Metges, M.A. and Wodad, A. (2005) Activity of Masticatory Muscles in Subjects with Different Orofacial Pain Conditions. Pain, 116, 33-341. http://dx.doi.org/10.1016/j.pain.2005.03.011

[24] Dahlstrom, L., Carlsson, S.G., Gale, E.N. and Jansson, T.G. (1985) Stress-Induced Muscular Activity in Mandibular Dysfunction. Journal of Behaviour Medicine, 8, 191-200. http://dx.doi.org/10.1007/BF00845520

[25] Lund, J.P., Donga, R., Widmer, C.G. and Stohler, C.S. (1991) The Pain-Adaptation Model: A Discussion of the Relationship between Chronic Musculoskeletal Pain and Motor Activity. Canadian Journal of Physiological Pharmacology, 69, 683-694. http://dx.doi.org/10.1139/y91-102

[26] Paesani, D.A., Tallents, R.H., Murphy, W.C., Hatala, M.P. and Proskin, H.M. (1994) Evaluation of the Reproducibility of Rest Activity of the Anterior Temporalis and Masseter Muscles in Asymptomatic Temporomandibular Subjects. Journal of Orofacial Pain, 8, 402-406.

[27] Majewski, R.F. and Gale, E.N. (1984) Electromyographic Activity of Anterior Temporalis Area Pain Patients and Non-Pain Subjects. Journal of Dental Research, 63, 1228-1231. http://dx.doi.org/10.1177/00220345840630101301

[28] Rapkin, A.J., Biggio, G. and Concas, A. (2006) Oral Contraceptives and Neuroactive Steroids. Pharmacology Biochemistry and Behavior, 84, 628-634. http://dx.doi.org/10.1016/j.pbb.2006.06.008 